\title{
Teoria da Ação Comunicativa e responsabilidade social empresarial: uma proposta de pesquisa ${ }^{1}$
}

\section{Communicative Action Theory and company's social responsibility: a research proposal}

Yvon Pesqueux ${ }^{2}$

Isabella Francisca Freitas Gouveia de Vasconcelos ${ }^{3}$

\begin{abstract}
Resumo
Neste artigo, empreendemos uma revisão da Teoria da Ação Comunicativa e propomos uma agenda de pesquisa sobre a adoção de fóruns de debate de inspiração habermasiana nas organizações, visando à fixação de agendas de desenvolvimento sustentável para diversos setores da economia. Como a responsabilidade social da empresa diz respeito à implementação, por parte dela, de ações de desenvolvimento sustentável, considera-se que deva estabelecer uma agenda de desenvolvimento sustentável tendo em vista sua atuação em setores específicos da economia. Assim, a pauta de desenvolvimento de produtos, serviços e tecnologias que obedeçam às diretrizes de desenvolvimento sustentável deve ser fixada de acordo com critérios substantivos a ser debatidos em fóruns de comunicação de inspiração habermasiana.
\end{abstract}

Palavras-chave: Comunicação. Ética. Desenvolvimento Sustentável. Inovação.

\begin{abstract}
In this paper, we undertook a review of the Communicative Action Theory and propose a research agenda on the adoption of Habermasian-inspired debate forums at organizations, aimed at setting sustainable development agendas for various sectors of the economy. As the company's social responsibility concerns the implementation, on its part, of sustainable development actions, one thinks there's a need for establishing a sustainable development agenda taking into account its operation in specific sectors of the economy. Thus, an agenda for developing products, services, and technologies which complies with the sustainable development guidelines should be set in accordance with the substantive criteria which are going to be debated on Habermasian inspired communication forums.
\end{abstract}

Keywords: Communication. Ethics. Sustainable Development. Innovation.

Artigo submetido em 25 de fevereiro de 2013 e aceito para publicação em 21 de março de 2013.

${ }^{1}$ Proposta do Grupo de Estudos TRANSFORMARE - Site: http://www.transformare.adm.br/, último acesso em 18/03/2013.

2 Doutor em Economia pela Universidade de Paris I; Professor titular do CNAM - Consevatoire National des Arts et Métiers, CNAMParis/França; Pesquisador e professor titular do LIRSA - Laboratoire Intercisciplinaire de Recherche en Sciences de L'Action, CNAMParis/França. Endereço: 292 Rue Saint Martin, Paris - França. E-mail: yvon.pesqueux@cnam.fr

${ }^{3}$ Doutora em Administração pela HEC-Ecola dês Hautes Etudes Commerciales, França; Professora titular do Centro Universitário da Fundação Educacional Inaciana - FEl; Professora associada e pesquisadora do LIRSA- Laboratorio Interdisciplinaire de Recherches en Sciences de L'Action, CNAM-Paris/França. Endereço: Centro Universitário da FEI - Rua Tamandaré, 688, CEP 01525-000, São Paulo - SP, Brasil. E-mail: Ivasconcelos@yahoo.com 


\section{Revisão das origens da Teoria da Ação Comunicativa: a crise da razão}

A chamada "Teoria da Ação Comunicativa" ou, em tradução direta do francês, "Ética da Comunicação", surgiu, como muitas iniciativas teóricas, com os estudos da chamada Escola de Frankfurt, cuja atividade principal estava em realizar uma reflexão filosófica e política sobre a sociedade alemã anterior e posterior ao nazismo.

A posição crítica fundamental desta escola conduziu alguns de seus autores, como Adorno e Horkheimer, a uma concepção pessimista da sociedade contemporânea. Eles viam sinais de não concretização de um projeto fundamental, o projeto da modernidade, do Iluminismo. Este fracasso da chamada era racional foi mostrado pelo triunfo passageiro e trágico do nazismo.

A queda dos valores fundamentais ligados ao Iluminismo, provocada pelo nazismo, trouxe a crise da razão, a ideia de que "[...] não se podia pensar mais depois de Auschwitz". Essa foi uma das questões centrais da Escola de Frankfurt. Desta forma, a história mostrava que a irracionalidade tornava-se regra em matéria de pensamento. Deste ponto de vista, para muitos autores, o genocídio confirmava o fracasso da visão racional do mundo, o que foi expresso de forma clara na declaração de Horkheimer (APEL, 1993, p. 30): "Nós não sabemos mais onde está a justiça, mas nós sabemos onde está o mal”.

Trata-se da crise da racionalidade e da metafísica, quando a razão fica reduzida à instrumentalidade, ao positivismo e ao cientificismo, pretendendo ser neutra do ponto de vista axiológico, apenas reconhecendo valores como os de eficiência e de utilidade.

“A razão é calculista. Ela pode estabelecer verdades de fato e relações matemáticas, mas nada mais. Na prática, ela apenas pode falar dos meios. Com respeito aos fins, ela deve se calar” (HORKHEIMER, 1987, p. 87, tradução nossa).

A crise da razão se manifesta em dois aspectos: um seria fundamentado, mas neutro, e o outro, ético (pressuposto kantiano), mas de ordem subjetiva, consequentemente, não verdadeiramente legítimo. Desta forma, segundo a proposta da Teoria da Ação Comunicativa, não é possível uma reflexão racional individual para o estabelecimento de objetivos e valores válidos moralmente.

Com a Teoria da Ação Comunicativa, Habermas (1987) propõe que razão e a ética vão estar reunidas de forma legítima. Para tanto, Habermas (1987) e Appel (1994) restabelecem o valor da razão mediante condições de legitimidade que se realizam por meio da comunicação intersubjetiva. Na proposta de Habermas está a superação de uma visão positivista bem como da crise da razão. "Ainda se pode pensar depois de Auchwitz". Segundo o pensamento habermasiano, a sociedade deve ser analisada e explicada de acordo com o que ela ainda não é. Com o estabelecimento de condições para a legitimidade da comunicação intersubjetiva, de acordo com o pensamento habermasiano, se chegará a uma ética comum a um grupo social.

\section{A Escolha entre duas Atitudes Racionais}

Há a exigência de uma ética racional afirmada diante das contradições da irracionalidade. Assim, é preciso fazer uma escolha entre duas atitudes racionais, escolha a ser esclarecida pela Teoria da Ação Comunicativa. Diante de uma constatação dos fatos, ou seja, da pluralidade de valores em nossa sociedade, observa-se a necessidade e a obrigação de tolerância com os diversos valores. A Teoria da Ação Comunicativa faz referência a Kant, mas se desenvolve com base no pensamento filosófico de Aristóteles.

A pluralidade de visões de mundo da sociedade é bem explicitada. Segundo Platão, existe uma visão de bem universal e transcendente. Já para Aristóteles, a experiência e a proposição do que é bom e dos valores 
associados ao bem estão relacionadas às diferentes experiências humanas e às diferentes formas de racionalidade.

Para Habermas (1987), a razão está ligada à moral, e a grande questão que se deve responder é "como ser moral”? Como se chegar à definição do que é o Bem? Como agir?

Ao contrário da proposta kantiana, como já vimos, a universalidade na definição dos valores e da ética não será atingida por meio de uma consciência moral solitária. Assim, a Teoria da Ação Comunicativa tem como proposta a superação do cientificismo e do positivismo e, logo, da razão puramente instrumental, bem como a superação de uma filosofia puramente baseada na consciência do sujeito.

A "verdade" não pode assim ser descoberta em uma simples relação "consciência-mundo", mas sim por meio de um diálogo que tenta, da mesma forma, estabelecer uma conexão com o mundo. A Justiça e a Verdade são estabelecidas de acordo com critérios estabelecidos pelo grupo social. Segundo Habermas, (1987, p. 45) “[...] a comunicação é a razão que nos une”. Trata-se, na verdade, de fazer surgir uma nova concepção da ética e da razão por meio de sua reunião em uma experiência que permite relacionar as duas: a comunicação.

A diferença em relação à proposta de Kant é, desta forma, clara, mesmo que, no plano do método, seja possível encontrar certa analogia.

\section{A Natureza Ética da Comunicação}

Como vimos, a necessidade de uma ética racional afirmada perante o império da ciência objetiva e dos abusos da irracionalidade confirmou-se pelo fato de que uma tal ética é pressuposta pela comunicação.

Segundo certos pressupostos, a comunicação visa superar uma concepção absoluta da verdade metafisicamente incerta e um relativismo que desqualificaria toda verdade universal.

Habermas (1987) distingue dois tipos de atividade: uma estratégica, que só tem por objetivo a eficiência ou o sucesso e que funciona mediante a ameaça de uma sanção ou a perspectiva de uma gratificação, e a ação comunicativa. Neste tipo de comunicação, o conceito de verdade não tem sentido.

A atividade comunicativa realmente desinteressada tem outra finalidade. A força da argumentação, nesta atividade, está no fato de que ela é capaz de gerar uma motivação racional distinta de um simples efeito de influência em relação a quem ela se dirige.

Habermas (1987) distingue assim os três grandes critérios de uma verdadeira comunicação:

- ou o mundo em questão é objetivo, aquele do estado das coisas existentes, e pode gerar um saber partilhado que exige uma obrigação de justificação no que diz respeito à verdade dos fatos;

- ou o mundo é social (conjunto de relações interpessoais legitimamente estabelecidas no seio do grupo social) e o critério de validade é o da justiça (do que é justo);

- ou o mundo é subjetivo pessoal (conjunto de proposições relativas à experiência vivida), e o critério de validade é o de sinceridade.

Nos três casos, o ato de comunicação faz referência a normas comuns ao locutor e ao auditor, sem as quais ele não pode existir de forma coerente e legítima. 
Tal ato pressupõe a existência de valores e de uma ética na qual ele se baseia. Assim que um debate se instaura, os interlocutores reconhecem implicitamente a existência de valores como a verdade dos fatos, a justiça dos atos e a sinceridade dos julgamentos. Se o interlocutor recusa a referência a estes princípios, a comunicação torna-se impossível. Da mesma forma que, na moral kantiana, a possibilidade de mentira destruiria toda moral.

Os princípios fundamentais da ética pressupõem então a existência de uma comunicação entre diferentes sujeitos ao termo de uma discussão bem conduzida. Não se tem ética sem comunicação e sem comunicação autêntica. A Teoria da Ação Comunicativa reúne assim ética e comunicação intersubjetiva dentro de um princípio de tolerância, democracia e ação política. Para que a ação comunicativa ocorra, além do cumprimento das regras de legitimidade explicitadas acima e de sua aceitação pelo grupo social que interage, é fundamental que a comunicação entre os membros do grupo seja feita com base em um princípio de igualdade de direitos. Como afirma Appel (1987, p. 94), "É esta exigência de um reconhecimento recíproco das pessoas como sujeitos de uma argumentação lógica e não apenas o uso lógico correto da capacidade de compreensão do indivíduo que justifica que se fale de uma 'ética da lógica’”.

Desta forma, analisando-se as diversas formas de comunicação, podem-se depreender quais os fundamentos morais que embasaram esta comunicação.

Assim, a Filosofia Moral tem uma função que é depreender a ética subjacente a cada forma de comunicação. No entanto, segundo Habermas, a função dos filósofos atualmente não é a de determinar em termos absolutos quais comportamentos adotar nesta ou naquela situação.

Tendo em vista o pluralismo totalmente justificado dos projetos e das diversas formas de vida, os filósofos não podem mais dar instruções universalmente válidas sobre o sentido da vida. Como filósofos, resta-lhes a atitude de análise reflexiva do procedimento graças ao qual se pode responder em geral às questões éticas. Ou seja, às formas de comunicação que conduzem à formulação de uma ética pelo grupo social. O significado do que representa um comportamento moral e antes de tudo moral, nós o apreendemos antes de toda filosofia. Isso ocorre em nossa piedade com relação à integridade ofendida de outro da mesma forma no sofrimento em relação à própria identidade ferida ou no medo que acompanha o ataque a esta forma de identidade. As experiências próprias à socialização primária relativas à proteção, à ajuda solidária e à equidade impregnam nossas intuições e nos educam bem mais do que poderiam fazer todos os argumentos possíveis. (HABERMAS, 1992, p. 164165).

O filósofo não pretende, desta forma, ditar ao homem comum a sua moral. Esta existe já nos seus atos antes de toda análise filosófica e ética. Kant também já havia constatado isso. A Filosofia, no entanto, tem a tarefa de compreender os pressupostos da moral e os seus critérios de legitimidade, os quais vão além das diversas formas de racionalidade, fazendo apelo a uma exigência de universalidade. Assim, a questão "quais são os critérios de legitimidade que produzem a comunicação entre os membros de um dado grupo social que produzirá o que é considerado ético para este grupo” pode ser respondida pelo filósofo.

Tendo em vista que o questionamento do filósofo da ética da discussão situa-se ao nível dos critérios de legitimidade, duas grandes questões colocam-se então: se os critérios de legitimidade da comunicação foram seguidos, se é possível a sua aplicação e sua realização (relação que existe entre pressupostos, princípios fundadores e realidade da ação moral). 


\section{A Base da Legitimidade da Razão Comunicativa}

A questão dos fundamentos de legitimidade da Teoria da Ação Comunicativa poderia ser expressa da seguinte maneira: por que ser moral, de forma geral? Esta questão é definida por Appel (1990) como o fundamento racional do ser moral.

J.M Ferry (1987) menciona que Appel, de seu lado, quer criar uma ética comunicacional com base em uma reflexão transcendente-pragmática, reforçando a necessidade, para o indivíduo que argumenta, de se conformar aos princípios do seu discurso. Pragmática porque se baseia em atos de linguagem, transcendental porque ligada, como em Kant, às condições e possibilidades destes atos. Segundo Appel (1994), é impossível, para um indivíduo, recusar a ética inerente ao fato de argumentar. Existem, assim, princípios normativos na base de toda ação comunicativa. Negar estas leis significa excluir-se da comunicação e da comunidade, negar seu status de sujeito de direito.

A seguir traçaremos o histórico do conceito de responsabilidade social de empresa e em seguida desenvolveremos uma reflexão sobre uma proposta habermasiana deste conceito. No término do artigo proporemos uma agenda de pesquisa.

A escola da Teoria da Ação Comunicativa se opõe ao relativismo contemporâneo. Em um mundo pluralista, a Teoria da Ação Comunicativa afirma a necessidade de encontrar critérios éticos que considerem a questão humana acima de preocupações unicamente ligadas ao conceito de comunidades. De fato, a corrente que defende as comunidades múltiplas afirma a existência da diversidade das culturas e da legitimidade de todas elas. Certas culturas afirmam ter sido excluídas no passado. Desta forma, o direito ao reconhecimento do outro torna-se um dever de exclusão em relação ao diferente, ao que não pertence a este grupo.

O reconhecimento da diversidade, o direito à diferença e a prática da tolerância conduzem à afirmação de um relativismo importante para a expressão das diversas culturas. Mas se deve buscar mais do que isso. A coexistência de culturas diferentes só pode ser legítima em direito e durável de fato se todos reconhecerem princípios comuns a todos que vão além da mera constatação da diversidade humana e do seu direito de se expressar. Existem, assim, elementos comuns a todos nós quando considerados seres humanos. Desta forma, os mesmos valores humanos fundamentais podem ser expressos de forma diferente de acordo com a cultura em questão. Quando se compreende que os seres humanos partilham os mesmos valores fundamentais de base, apenas exprimindo-os de forma diversa dependendo da cultura em questão, é possível encontrar-se possibilidades de diálogo entre as diversas culturas. Assim, elementos universais como o respeito aos direitos humanos, os direitos constitucionais e legais atribuídos a todos, entre outros, devem estar acima da preocupação consigo ou com a sua cultura particular.

O interesse da Teoria da Ação Comunicativa para a administração de empresas reside na tentativa de conciliação relativa à pluralidade de nossas sociedades e a exigência de uma universalidade afirmada por meio da ética. Na empresa, este conceito conduz à necessidade não de uma simples tolerância, mas de um debate que pode levar a um acordo que seria símbolo de certo tipo de universalidade de direitos e interesses. O caráter universal deste acordo é conquistado por intermédio do confronto de ideias. Assim, a importância do discurso como base ética, contra a violência, poderia ser traduzida como o reconhecimento da negociação, parte essencial da fundação desta empresa. Empresa e ética pressupõem a existência de formas de pensamentos diferentes, conflitos possíveis, mas debates criativos e fecundos, com a condição, no entanto, de que a comunicação que se manifesta nestas discussões seja uma verdadeira comunicação.

Habermas (1990) desta forma, reconhece a importância da comunicação, inclusive na empresa. Relaciona-a, entretanto, a uma exigência e a uma obrigação de "verdade”, que é a base do seu conceito de racionalidade e o faz rejeitar formas de comunicação puramente estratégicas e instrumentais. É possível existir este tipo de racionalidade nas empresas, porém em contextos específicos. 
A Teoria da Ação Comunicativa oferece um paradigma de racionalidade que não é mais aquele da razão positivista, científica, objetiva e neutra e nem aquele de uma razão estratégica, manipuladora e instrumental, mas o de uma razão prática. Esta racionalidade é especialmente visível na atividade comunicativa, mas pode ser exercida de forma bem mais extensiva em todo o campo da Ética. Assim, a ação comunicativa repousava na afirmação de uma racionalidade ética face aos exageros do positivismo e do subjetivismo, bem como dos exageros da irracionalidade. A ideia é que por intermédio da comunicação pode-se determinar o que é justo para o grupo social, além da busca da realização pessoal e de expressão de diferentes culturas. Há nas empresas espaço para a busca por ética e responsabilidade social.

Faremos a seguir uma breve revisão do conceito de responsabilidade social da empresa, e em seguida proporemos uma visão habermasiana deste conceito.

\section{A Emergência do Conceito de Responsabilidade Social das Empresas (RSE)}

Os americanos preocuparam-se bastante cedo com as questões de ética e de moral dentro da empresa: ao final do século XIX já nasce a noção de responsabilidade social da empresa por meio da qual se interroga sobre as relações entre a empresa e a sociedade (ACQUIER e AGGERI, 2008). Ao início do século XX, o debate começa a ser mais estruturado com a generalização do modelo da grande empresa a acionário disperso (HEALD, 1970; EPSTEIN, 2002 apud ACQUIER e AGGERI, 2008). Em 1938, Barnard, em The Functions of the Executive, confere ao dirigente uma função moral: deve criar códigos de ética assim como suscitar um clima favorável à "floração de condições morais" (GOND e MULLENBACH-SERVAYRE, 2004, p. 57).

Em 1970 Milton Friedman escrevia que a única responsabilidade social da empresa é gerar lucro. Essa ideia era apoiada por outros autores, como Wartick e Cochran (1985) e (MCGEE, 1998). O modelo Friedman centrava-se sobre o controle dos custos de agência, que reduzia a responsabilidade do manager unicamente à maximização dos juros dos acionistas (MCGEE, 1998).

Ao contrário, conforme explica Reynaud (2008), outros autores como Freeman (1984), acreditavam que a satisfação das partes interessadas garantia o bom funcionamento da empresa e, assim, o seu rendimento. Deste modo, a RSE consiste em "[...] identificar e satisfazer os interesses daqueles que são afetados pelas ações da organização” (MACLAGAN, 1998 apud REYNAUD, 2008, p. 93). Autores como McGuire (1963), Davis (1973), Stone (1975), conferem às empresas uma obrigação de responsabilidades sociais que vão além das obrigações econômicas, contratuais ou legais. Em 1972, Manne e Wallich (apud REYNAUD, 2008) adicionam a esta perspectiva um novo dado: a decisão de cada empresa de estender as suas responsabilidades e de responder às expectativas da sociedade tem de ser puramente voluntária.

\section{A teoria das partes interessadas (ou Intervenientes) (TPI)}

Este conceito, presente pela primeira vez na literatura do management em uma nota do Stanford Research Institute (SRI), em 1963, estende a noção de stockholder (os acionistas) aos grupos "[...] sem o suporte dos quais a empresa não poderia existir” (STANFORD RESARCH INSTITUTE, 1963 apud GOND e MULLENBACH-SERVAYRE, 2004). A empresa tem então uma responsabilidade para com esses grupos, chamados a partir daquele momento de stakeholders, ou seja, "partes interessadas” (acionários, assalariados, consumidores, fornecedores, detentores dos capitais da sociedade, clientes etc.). O termo vai se desenvolver a partir do final dos anos 1970 e começo dos anos 1980, como as técnicas gerenciais da corporate social responsiveness (ACQUIER e AGGERI, 2008). O termo vai instituir uma verdadeira teoria que conceitua principalmente a noção de RSE. 
Freeman (1984) apud Acquier e Aggeri (2008), definiam o stakeholder como “[...] qualquer grupo cujo comportamento coletivo pode afetar de modo direto o futuro da organização, mas que não está abaixo de controle direto do diretor presidente ou conselho de administração” (ACQUIER e AGGERI, 2008, p. 78). Deste modo, Freeman formaliza em 1984 o stakeholdermodel e propõe uma alternativa àqueles que não concordam com o shareholdermodel (BARET, 2006). Com o seu stakeholdermodel, Freeman converte o seu manager no avalista dos interesses de todas as partes interessadas, ao risco de reduzir o retorno sobre o investimento dos acionários. Assim, a nova missão é a de estabelecer uma "[...] governança socialmente responsável que iria além da simples coexistência aceitável entre stakeholders” (BARET, 2006, citando o relatório da Comissão Europeia, em 2001, p. 135).

A empresa torna-se responsável no relacionamento com todos os seus sócios, quer sejam internos (acionários e assalariados) ou externos (contratantes, clientes, fornecedores, vizinhos, comunidades locais, financeiras, bancos etc.). A firma tem também responsabilidades mais abrangentes, a RSE é considerada como um corolário de uma boa gestão, ou seja, de uma gestão estratégica e ética que reconhece as necessidades de todos os atores que têm interesse na empresa e que avaliam as consequências dos seus atos (GOND e MULLENBACH-SERVAYRE, 2004).

Segundo a teoria das partes interessadas as organizações econômicas não são unicamente submetidas a uma obrigação de legitimidade e de justiça. Para Freeman (1984) apud ACQUIER ET AGGERI (2008), o objetivo da TPI seria o de questionar a separação entre um mundo econômico dominado pelo interesse e o oportunismo e um mundo ético marcado pela pesquisa do bem comum e da equidade (DUPUIS, 2008). A TPI representa um avanço considerável na área da RSE, permitindo assim conceituar o ambiente da empresa; os trabalhos de Freeman marcaram a RSE, identificando, por exemplo, o "outro", aquele com quem a empresa tem de se responsabilizar (PASQUERO, 2005 apud LAPRISE, 2006).

\section{A pirâmide das necessidades}

Em 1983, Carroll escrevia que a responsabilidade social era um modo de administrar a empresa de forma que fosse lucrativa, respeitasse a lei e a ética. Como explicam Golli, Micheletti e Yahiaoui (2010), para Carroll, gerar lucros e respeitar a lei são duas condições essenciais para compreender a adequação de uma empresa com relação à ética e à sociedade na qual opera.

A pirâmide das necessidades de Carroll (1991) parece ter sido o modelo mais usado. Este modelo, seguindo a ideia de Freeman (1984), imputa também à empresa outros valores além do monetário: a responsabilidade social das empresas cobre as esferas econômicas, legais, éticas e discricionárias que a sociedade tem em um dado momento (CARROLL, 1991 apud GOLLI, MICHELETTI e YAHIAOUI, 2010). No modelo que estabelece em 1991, Carroll hierarquiza os quatro tipos de "obrigação", de responsabilidades, que as empresas têm, sendo principalmente econômicas (base da pirâmide), legais, éticas e filantrópicas (parte de cima da pirâmide, ver Figura 1). 
Figura 1

\section{Responsabilidade Social Corporativa segundo Carroll}

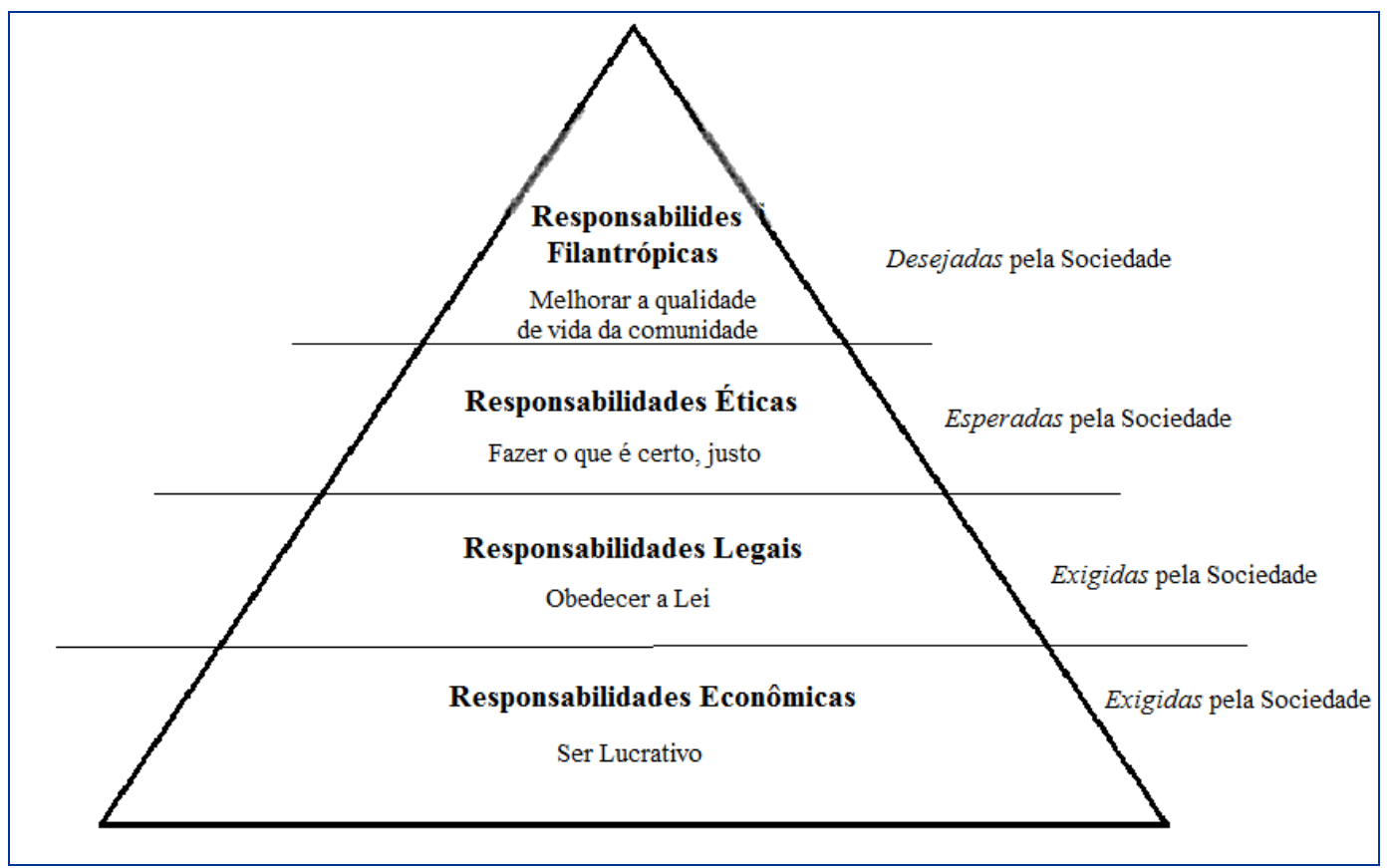

Fonte: Golli, Micheletti e Yahiaoui, 2010.

As responsabilidades econômicas de uma empresa são a sua razão de ser: trata-se de satisfazer os consumidores propondo produtos e serviços, fazendo assim um benefício e assegurando a perenidade da empresa. A segunda responsabilidade é legal: há que atuar respeitando a lei. A empresa tem também de se comportar de modo ético. Para Carroll, essas responsabilidades obrigam a empresa a fazer o que é percebido como certo, justo e honesto. Na parte de cima da pirâmide encontram-se as responsabilidades filantrópicas da empresa, que consistem em implementar ações capazes de melhorar a qualidade de vida dos assalariados, da comunidade local ou da sociedade (CRANE e MATTEN, 2004 apud GOLLI, MICHELETTI e YAHIAOUI, 2010).

Para Carroll, as duas primeiras responsabilidades são exigidas pela sociedade, a terceira é esperada e a quarta, desejada (GOLLI, MICHELETTI e YAHIAOUI, 2010).

\section{O Futuro da Responsabilidade Social das Empresas numa Perspectiva de Desenvolvimento Sustentável}

O conceito da RSE segue evoluindo desde a sua criação, passando de um conceito teórico a um conceito cada vez mais prático, já que hoje se desenvolve numa perspectiva de desenvolvimento sustentável (DS), fenômeno cuja importância não parou de crescer desde a sua conceituação.

Em 1983, a Assembleia Geral das Nações Unidas requeria à Comissão Mundial sobre o Meio Ambiente e Desenvolvimento a proposição de novas estratégias na área do meio ambiente para assegurar um desenvolvimento capaz de preservar o planeta no ano 2000 e no futuro. Trata-se também de recomendar diretrizes aos países em desenvolvimento e países desenvolvidos do ponto de vista econômico e social com vista à união e cooperação no combate aos problemas ligados ao meio ambiente. Desse modo, nasceu em 1987 o Relatório Brundtland, originado da Presidente da Comissão, a norueguesa Harlem Brundtland. Esse 
relatório fixa as bases do desenvolvimento sustentável, listando as políticas e comportamentos necessários para permitir à sociedade se desenvolver dando tanta importância às práticas econômicas quanto às práticas do meio ambiente e às práticas sociais. A expressão de "desenvolvimento sustentável", "sustainabledevelopment", nasceu deste relatório, assim como a sua definição: o desenvolvimento sustentável é “[...] o desenvolvimento que procura satisfazer as necessidades da geração atual, sem comprometer a capacidade das gerações futuras de satisfazer as suas próprias necessidades” (RELATÓRIO BRUNTLAND, 1987, p. 49).

Para Laprise (2009), o desenvolvimento sustentável é um conceito de sucesso, "eixo filosófico popular" do final do século XX e do começo do século XXI. Laprise explica que, para alguns autores (CAPRON e QUAIREL-LANOIZELÉE, 2004), a manifestação do desenvolvimento sustentável sob diferentes formas deve-se ao renascimento do conceito de RSE. Existe, então, um vínculo entre o desenvolvimento sustentável e a RSE, sendo possível considerar esta última como a aplicação dos princípios do DS no mundo da empresa. A RSE significa, sobretudo, que as empresas contribuem voluntariamente para melhorar a sociedade e proteger o meio ambiente, em associação com as partes interessadas, numa perspectiva de desenvolvimento sustentável. O conceito de DS parece ter um papel importante no desenvolvimento das práticas empresariais ligadas ao meio ambiente (LAPRISE, 2009).

Os conceitos de DS e RSE estão ligados e são fundamentais atualmente no que se refere ao meio ambiente e à sustentabilidade. Laprise (2009) explica a evolução do conceito de DS e RSE. Os autores consideram que o desenvolvimento sustentável traduz uma mudança de direção reivindicada por autores e por instituições que desejam romper com o modelo de desenvolvimento industrial. Para os autores, a convergência das necessidades e dos interesses desses atores e instituições alimenta o sucesso do tema desenvolvimento sustentável nas pesquisas atuais (GENDRON et al., 2005).

Busca-se hoje integrar a RSE à nova dinâmica do desenvolvimento sustentável, já que este faz parte das principais preocupações dos governos, das populações e também dos dirigentes de empresa que se vêm obrigados a levá-lo em conta se querem ter legitimidade.

Para se integrar verdadeiramente numa lógica de desenvolvimento sustentável, a teoria sobre a RSE teria que ser construída em três fases: apropriação das problemáticas do desenvolvimento sustentável dentro da governança da empresa; controle do estado das empresas com respeito a tais problemáticas; e estímulo às inovações tendo em vista a mudança do modelo organizacional para que as empresas sejam mais "sustentáveis". Deste modo, integrando-se a essa lógica de desenvolvimento sustentável, a RSE termina por se consolidar. Assim, parece que começa a se constituir um verdadeiro vínculo entre a empresa e a sociedade: criar valor, mas respeitando-se ao mesmo tempo a sociedade e o meio ambiente - a RSE seria o melhor modo para os diferentes atores agirem em uma sociedade globalizada (D’HUMIÈRES, 2010).

Na proposta de desenvolvimento sustentável está subjacente a ideia de esperança: a preservação do meio ambiente e da sociedade para as gerações futuras.

O conceito de responsabilidade social diz respeito à implementação de ações voltadas para o desenvolvimento sustentável. Em documento oficial da ONU, a responsabilidade social é assim definida: “A responsabilidade Social de Empresa diz respeito às ações de gestão responsáveis pelo estabelecimento de metas empresariais que impulsionem o desenvolvimento sustentável da sociedade, preservando recursos ambientais e culturais para as gerações futuras, respeitando a diversidade e promovendo a redução das desigualdades sociais”. (COMISSÃO MUNDIAL SOBRE MEIO AMBIENTE E DESENVOLVIMENTO, 1991, p. 5).

Ações de responsabilidade social nas empresas fixariam agendas de desenvolvimento em termos de tecnologia, produtos e serviços que correspondessem à seguinte pauta de desenvolvimento sustentável: 
(a) Retomar o crescimento como condição necessária para erradicar a pobreza;

(b) Mudar a qualidade do crescimento para torná-lo mais justo, equitativo e menos intensivo em matérias-primas e energia;

(c) Atender às necessidades humanas essenciais de emprego, alimentação, energia, água e saneamento;

(d) Manter um nível populacional sustentável;

(e) Conservar e melhorar a base de recursos;

(f) Reorientar a tecnologia e administrar os riscos; e

(g) Incluir o meio-ambiente e a economia no processo decisório.

Fonte: (COMISSÃO MUNDIAL SOBRE MEIO AMBIENTE E DESENVOLVIMENTO, 1991, p. 53).

Na medida do possível, as empresas, ao fixar os conteúdos de suas políticas de expansão e desenvolvimento, deveriam levar em conta estas diretrizes. O mesmo vale para o estabelecimento de políticas e diretivas de desenvolvimento de setores específicos da economia.

É possível criar-se nos setores institucionais e nas empresas fóruns de discussão estruturada, de inspiração habermasiana, por meio dos quais se fixem as agendas de desenvolvimento sustentável. Ao menos em uma primeira instância, é preciso buscar critérios mais substantivos para a fixação das pautas de desenvolvimento (tecnologias, produtos, serviços, ações de P\&D e Inovação etc.) tendo em vista o mérito das propostas para desenvolvimento social e humano de acordo com as políticas de responsabilidade social da empresa. Em um segundo momento preocupações voltadas para eficiência e lucratividade seriam consideradas, depois de fixadas prioridades de acordo com critérios mais amplos norteados pelas diretrizes de desenvolvimento sustentável.

A "ética da discussão" oferece um paradigma da racionalidade que não é aquele da razão positiva, científica, objetiva e axiologicamente neutra, nem aquele de uma razão estratégica, manipuladora e instrumental, mas aquele de uma racionalidade prática. Ela é principalmente visível na atividade comunicacional, pode ser exercida, no entanto, de maneira bem mais ampla em todo o campo ético. Vimos claramente que o projeto da "ética da discussão" repousava primeiramente na afirmação de uma racionalidade ética diante das derivações do subjetivismo e do irracionalismo. A abordagem da "ética da discussão" leva precisamente ao reconhecimento de uma razão que possa ser aplicada ao campo dos fins e não mais somente ao dos meios, à determinação do "justo" e não apenas à definição da "vida boa". É, portanto, de uma verdadeira racionalidade prática que se trata, racionalidade cujas manifestações poderíamos ver no mundo da empresa.

\section{Referências}

ACQUIER, A; AGGERI, F. Une genealogie de la pensée manageriale sur la RSE. Revue Française de Gestion, v. 38, n. 180, p. 131-157, 2008.

APPEL, K. O. L'éthique à l'âge de la science. Lille: PUL, 1987.

Penser avec Habermas contre Habermas. Paris: L’éclat, 1990.

Ethique de la discussion. Cerf. collection Humanités, Paris, 1994.

BARET, P. L’évaluation contingente dela Performance globale des entreprises: une méthode pour fonder un management sociétalement responsable? In: ROSE, J-J. (Ed.). Responsabilité sociale del'entreprise, pour un nouveau contrat social. Bruxelles: De Boeck \& Larcier, 2006. p. 135-152. 
BRUNDTLAND, G. H. Our common future: report of the world commission on environment and development. New York: Oxford University, 1987.

CAPRON, M.; QUAIREL-LANOIZELÉE, F. Mythes et réalités de l’entreprise responsable. Paris: La Découverte, 2004.

D’HUMIÈRES, P. Le développement durable va-t-il tuer le capitalism. Paris: Maxima, 2010.

DUPUIS, J. C. La RSE, de la gouvernance de la firme à la gouvernance de reseau. Revue Française de Gestion, v. 38, n. 180, p. 159-175, 2008.

EMSHOFF, J. R; FREEMAN, R. F. Stakeholder management. Working paper from the Wharton Applied Research Center, 1978.

FERRY, J-M. Habermas: l’éthique de la communication. Paris : PUF, Coleção Recherches Politiques, 1987

FREDERICK, W. C. Theories of corporate social performance. In: SETHI, S. P.; Falbe, C. M. (Eds.). Business and society. Lexington: Lexington Books, 1987.

FREEMAN, R. E. Strategic management: a stakeholder approach. Boston: Pitman, 1984.

FRIEDMAN, M. The social responsibility of business is to increase profits. New York Times Magazine, New York, p. 32-33, 13 Sept. 1970.

GOLLI, A. ; MICHELETTI, P. ; YAHIAOUI, D. In : BRY, F.; IGALENS, J.; PERETTI, J-M (Coords.). Éthique et responsabilité sociale, 78 experts témoignent - mélanges en l’honneur de Michel Joras. Cormelles le Royal, France: Editions EMS, 2010. p. 133-140.

GOND, J-P.; MULLENBACH-SERVAYRE, A. Les fondements théoriques de la responsabilité sociétale de l'entreprise. La Revue des Sciences de Gestion: Direction et Gestion, Jan./Feb., p.93, Paris, 2004.

HABERMAS, J. Théorie de l’agir communicationnel. Paris: Fayard, Paris, 2 Tomos, 1987.

Ethique de la discussion. Paris: Cerf., 1992.

MCGEE, J. Corporate strategies and environmental regulations: an organizing framwork. In: RUGMAN, A.M.; VERBEKE, A. Strategic Management Journal, v. 19, p. 377-987, 1998.

REYNAUD, E. et al. La responsabilité sociale de l'entreprise à l'épreuve de l'Europe. Revue française de gestion, n. 180, p. 109-130, 2008/1.

VASCONCELOS, I. F. F. G.; MASCARENHAS, A. O isomorfismo estrutural e os limites da normalização: dois estudos de caso sobre a implementação das normas ISO 9000 em empresas de informática na França. Eneo, ANPAD, Curitiba, Brasil, 2000. 